\title{
Attenuation of Astroglial Reactivity by Interleukin-10
}

\author{
Vijayabalan Balasingam and Voon Wee Yong \\ Montreal Neurological Institute, Department of Neurology and Neurosurgery, McGill University, Montreal, \\ Quebec, Canada H3A 2B4
}

Prominent responses that follow brain trauma include the activation of microglia, the recruitment of blood-derived macrophages, and astroglial reactivity. Based on evidence that cytokines produced by macrophages/microglia may cause astrocytes to become reactive, the aim of this study was to determine whether astroglial reactivity could be attenuated by interleukin (IL)-10, a potent inhibitor of cytokine synthesis by macrophages/microglia. Four days after the local application of $\mathrm{IL}-10$ to the site of corticectomy in adult mice, the number of reactive astrocytes and their state of hypertrophy was reduced (by $60 \%$ ) when compared with vehicle controls. In the majority of IL-10-treated mice, but not in any vehicle controls, the tissue in the immediate vicinity of IL-10 application contained viable but nonreactive astrocytes. The mechanism by which IL-10 attenuates astroglial reactivity is likely via the reduction of cytokine production by macrophages/microglia because, based on Mac-1 immunohistochemistry, the macrophages/microglia of IL-10 brains had a decreased activation state compared with vehicle-treated controls. Another macrophage/microglia deactivating agent, macrophage inhibitory factor, also reduced astroglial activity in vivo. Furthermore, IL-10 had no direct effect on purified astrocytes in culture, indicating that its in vivo action on astroglial reactivity is likely via indirect mechanisms. Finally, injury resulted in the substantial rise of tumor necrosis factor- $\alpha$ mRNA levels, and this elevation was significantly inhibited by IL-10. The ability to manipulate the extent of astrogliosis should provide a means of addressing the neurotrophic or inhibitory role of reactive astrocytes in neurological recovery.

Key words: CNS trauma; gliosis; interleukin-10; microglia; reactive astrocytes; $T N F-\alpha$
Astroglial reactivity is a characteristic manifestation of brain pathology after many types of insults to the adult CNS (Norton et al., 1992; Eng and Girnikar, 1994). Reactive astrocytes become larger, extend thicker, longer processes, increase their level of detection by immunohistochemistry of glial fibrillary acidic protein (GFAP), and upregulate their number of mitochondria, glycogen content, and various enzyme levels (Nathaniel and Nathaniel, 1981; Norenberg, 1994). A long-term result of this astrocytic reaction can be the formation of a densely interwoven glial scar at the lesion site, which has been thought to be detrimental to axonal regeneration (Reier et al., 1983; Liuzzi and Lasek, 1987). On the other hand, more recent evidence suggests that astroglial reactivity may actually be an attempt by these cells to promote CNS recovery; in particular, neurotrophic factors are produced around the locus of CNS lesions, especially in the early phase of astroglial reactivity (Nieto-Sampedro et al., 1982; 1983; Needels et al., 1986; Ip el al., 1993) (for review, see Yong, 1996). Thus, the ability to manipulate the extent and the occurrence of astroglial reactivity can have implications for CNS regeneration.

Anisomorphic injuries in the adult, involving trauma with disruption of the blood-brain barrier, result in the activation of intrinsic microglia and the recruitment of systemic inflammatory mononuclear cells, including monocytes (which become macrophages after entry into the tissue), to the lesion site (Kitamura et

\footnotetext{
Received Aug. 9, 1995; revised Feb. 13, 1996; accepted Feb. 14, 1996.

This work was supported by the Medical Research Council of Canada. V.B. is the recipient of a scholarship from the Canadian Network for Neural Regeneration and Functional Recovery, one of 15 networks of Centres of Excellence supported by the government of Canada. We thank Maria Rostworowski and Jolanda Turley for skilled technical assistance.

Correspondence should be addressed to Dr. Voon Wee Yong, Montreal Neurological Institute, 3801 University Street, Montreal, Quebec, Canada H3A 2B4.

Copyright (C) 1996 Society for Neuroscience $0270-6474 / 96 / 162945-11 \$ 05.00 / 0$
}

al., 1972; Tsuchihushi et al., 1981; Boya ct al., 1986; Giulian, 1987; Moorshead and van der Kooy, 1990; Leong and Ling, 1992). These inflammatory cells are a rich source of pro-inflammatory cytokines as determined by the elevated content of the macrophage-derived cytokines interleukin (IL)-1, IL-6, and tumor necrosis factor (TNF)- $\alpha$ after trauma (Woodroofe et al., 1991; Yan et al., 1992; da Cunha et al., 1993; Taupin et al., 1993; Quan et al., 1994). The rise in the recruitment of macrophages/microglia is followed by the appearance of local astroglial reactivity (Giulian et al., 1989; Balasingam et al., unpublished observations). Further evidence to implicate macrophages/microglia (and especially their secretory cytokine products) as mediators of astroglial reactivity is provided by the observation that the administration of IL-1, TNF- $\alpha$, or interferon- $\gamma$ (IFN- $\gamma$ ), a potent stimulator of macrophage activity, into the site of CNS trauma increases astroglial reactivity beyond that induced by trauma alone (Giulian et al., 1988; Brosnan et al., 1989; Watts et al., 1989; Yong et al., 1991). In addition, although an acute injury (e.g., stab) to the neonatal brain creates minimal astroglial reactivity in contrast to adults (Sumi and Hager, 1968; Berry et al., 1983; Barrett et al., 1984; Maxwell et al., 1990), appropriate insults can elicit extensive astroglial reactivity (Balasingam et al., 1994); the occurrence or absence of reactive astrocytes in neonatal animals is correlated, respectively, with the presence or lack of activated macrophages/ microglia at the lesion site (Balasingam et al., unpublished observations). Finally, the minimal astroglial reactivity after a stab injury to the neonatal brain can be converted to extensive reactivity by the single microinjection of macrophage-derived cytokines (IL-1 or TNF- $\alpha$ ) (Balasingam et al., 1994).

Given the above evidence implicating macrophages/microglia in astroglial reactivity, we have addressed whether astroglial reactiv- 
ity could be attenuated by inhibiting cytokine production by macrophages/microglia. We selected IL-10 for this purpose because IL-10, also named cytokine synthesis inhibitory factor, is a potent inhibitor of cytokine secretion by macrophages/microglia (Bogdan et al., 1991; de Waal Malefyt, 1991a; Fiorentino et al., 1991a; D’Andrea et al., 1993; Mosmann, 1994). We demonstrate that the administration of IL-10 attenuates the astroglial reactivity that follows corticectomy in the adult mouse brain.

\section{MATERIALS AND METHODS}

\section{Experimental animals}

Adult retired female breeders of the CD1 strain (4-6 months old) were obtained from a commercial source (Charles River Canada, Montreal, Quebec, Canada). Animals were housed on a 12/12 hr light/dark cycle with ad libitum access to food and water. All experimental procedures were approved by the institution's animal care committee and were in accordance with the guidelines instituted by the Canadian Council of Animal Care.

Animals were anesthetized with an intraperitoneal injection containing a mixture of ketamine $(200 \mathrm{mg} / \mathrm{kg})$ and xylazine $(10 \mathrm{mg} / \mathrm{kg})$. The animals were immobilized in a stereotaxic frame followed by a midline incision and a unilateral circular ( $\sim 3 \mathrm{~mm}$ diameter) craniectomy over the left hemisphere. A $25-30 \mathrm{~mm}^{3}$ volume of cortical tissue was removed by vacuum aspiration, and the wound cavity was packed with Gelfoam (Upjohn, Kalamazoo, MI; $50 \mathrm{~mm}^{3}$ volume when dry) soaked in $20 \mu \mathrm{l}$ of test agent. The skin was closed with 4.0 sutures. Animals received recombinant murine IL-10 (PeproTech, Rocky Hill, NJ; specific activity of $10^{7}$ $\mathrm{U} / \mathrm{mg}$ protein and containing no carrier proteins) of specified doses: 25 , 50,100 , and $200 \mathrm{U}$. Control animals received Gelfoam containing PBS, which was the vehicle for IL-10. This method of administering test agents by using Gelfoam has been described previously (Yong et al., 1991) and is thought to produce a slow release of agent into the parenchyma. Animals were allowed to survive for $4 \mathrm{~d}$ postoperatively.

\section{Cajal's gold chloride sublimate method for astrocytes}

This classical method was used for its ability to demonstrate three types of astrocytes: the normal protoplasmic astrocyte present in gray matter (e.g., cortex) (Fig. 1A), the fibrous astrocyte present in normal white matter (e.g., corpus callosum) (Fig. $1 B$ ), and the reactive astrocyte (Fig. $1 C)$ that can be derived from either protoplasmic or fibrous astrocytes through hypertrophy and extension of processes. In contrast, the more current method of GFAP immunoreactivity (GFAP-IR) readily reveals normal fibrous astrocytes and reactive astrocytes, but not normal protoplasmic astrocytes in the cortex (Bignami and Dahl, 1976; Yong and Balasingam, 1995). According to Vaughn and Pease (1967), as well as Mori and Leblond (1969), the Cajal gold chloride sublimate stain deposits gold on the astroglial filaments contained in astrocytes, thereby facilitating the light microscopic evaluation of the different types of astrocytes.

Brains from decapitated animals were fixed in formalin-ammonium bromide ( $2 \%$ ammonium bromide and $15 \%$ formalin in water) $(\mathrm{v} / \mathrm{v})$ solution for $24 \mathrm{hr}$. Frozen sections were cut at $20 \mu \mathrm{m}$ and received in distilled water containing 10 drops of formalin. After 2 washes in distilled water, the sections were laid flat in the gold chloride sublimate solution ( $2 \%$ mercuric chloride and $0.25 \%$ of aqueous gold chloride solution) $(\mathrm{v} / \mathrm{v})$ for $24 \mathrm{hr}$. Sections were removed, washed in water followed by $5 \%$ sodium thiosulphate, and washed in water again; each wash was of $5 \mathrm{~min}$ duration. Sections were mounted on clean albuminized slides, allowed to dry, and mounted with Eukitt (O Kindler, Freiburg, Germany).

\section{Assessment of GFAP-IR in situ}

Fluorescent GFAP-IR. Animals were anesthetized and exsanguinated intracardially followed by post-fixation and cryoprotection of the brain as reported earlier (Balasingam et al., unpublished observations). Twenty micrometer coronal sections were obtained on gelatin-coated slides and subjected to immunofluorescence for GFAP, as described previously (Balasingam et al., 1994). Three representative sections per animal were photographed with a $10 \times 0.30$ numerical aperture objective on a Reichert Polyvar 2 microscope (Leica, Nussloch, Germany) for quantitative purposes. Only GFAP-IR astrocytes with processes and a clearly stained soma were counted.

Nonfluorescent GFAP-IR. Brains were removed after decapitation and fixed in $10 \%$ formalin overnight and embedded in paraffin. Six microme-

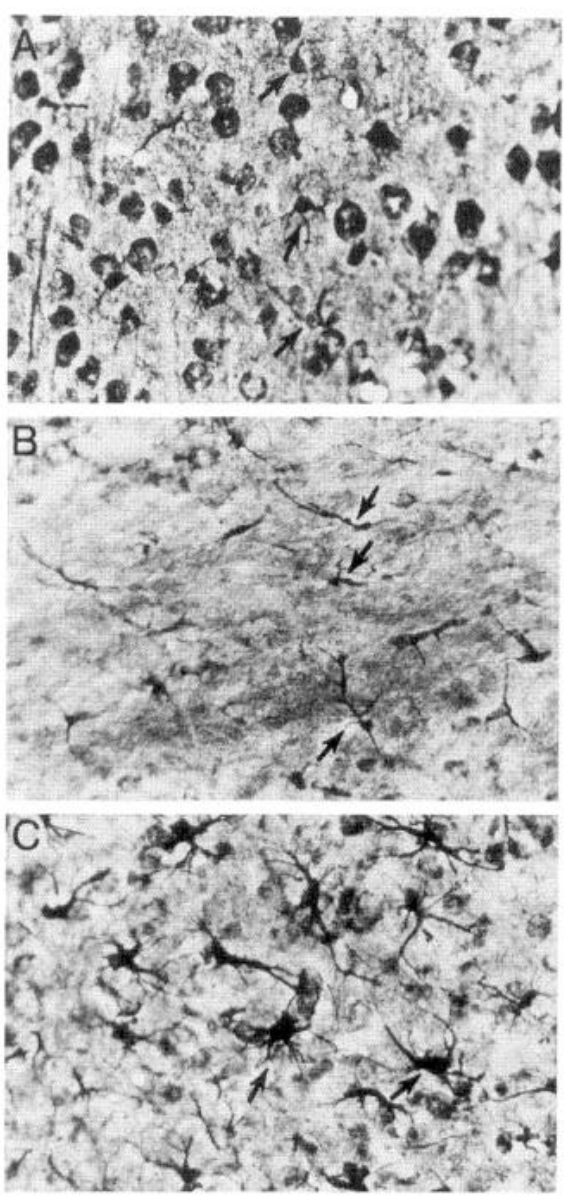

Figure 1. Cajal's gold chloride sublimate technique to identify normal and reactive astrocytes. Some astrocytes in all three frames are indicated by arrows. $A$, Protoplasmic astrocytes in the gray matter of the uninjured cortex. The darkly stained round structures are neuronal soma. To visualize normal protoplasmic astrocytes in the cortex, it is necessary to overstain brain sections, and this results in the neuronal cell bodies being darkly labeled. In contrast, after injury, astrocytes can be easily revealed without the need for overstaining (e.g., in frame $C$; thus, neuronal cell soma in $C$ is not prominent). $B$, Fibrous astrocytes in the uninjured corpus callosum. $C$, Reactive astrocytes in the cortex after traumatic injury. Magnification, $400 \times$. It has been our experience that the Cajal method, compared with GFAP/Mac-1 immunofluorescence or GFAP immunoperoxidase-AEC methods, amplifies the differences in depth of field; this contributes to some of the cells appearing out of focus in this figure.

ter coronal sections were obtained, deparaffinized in xylene, rehydrated in a decreasing gradient of ethyl alcohol, and placed in water. Endogenous peroxidase was quenched with a $3 \% \mathrm{H}_{2} \mathrm{O}_{2}$ solution, and the sections were incubated with Protein Block (Immunon, Pittsburgh, PA) before incubation with a rabbit anti-GFAP polyclonal antibody (1:100, Dako, Glostrup, Denmark) for $30 \mathrm{~min}$ at room temperature. Sections were then incubated with a biotinylated secondary antibody followed by streptavidin peroxidase and revealed by AEC chromogen (Immunon; prepared per manufacturer's instructions). All sections were rinsed in Tris buffer before each of the succeeding steps, which were performed for $30 \mathrm{~min}$ at room temperature. Sections were counterstained with Harris' hematoxylin and coverslipped with Gelvatol.

\section{Mac-1 immunofluorescence}

The primary antibody used was a monoclonal rat anti-mouse immunoglobulin to Mac-1 (complement receptor, type three) antigen. Immunohistochemistry was performed at room temperature on $20 \mu \mathrm{m}$ brain sections (obtained as described for GFAP-IR). In brief, samples were initially fixed in acetone for $20 \mathrm{~min}$, blocked with chicken egg albumin (3\%) for $30 \mathrm{~min}$, and incubated overnight with the primary antibody (10 $\mu \mathrm{g} / \mathrm{ml}$ ) at room temperature. Sections were then sequentially incubated with biotinylated anti-rat immunoglobulin (1:100, Dako) for $1 \mathrm{hr}$, fol- 


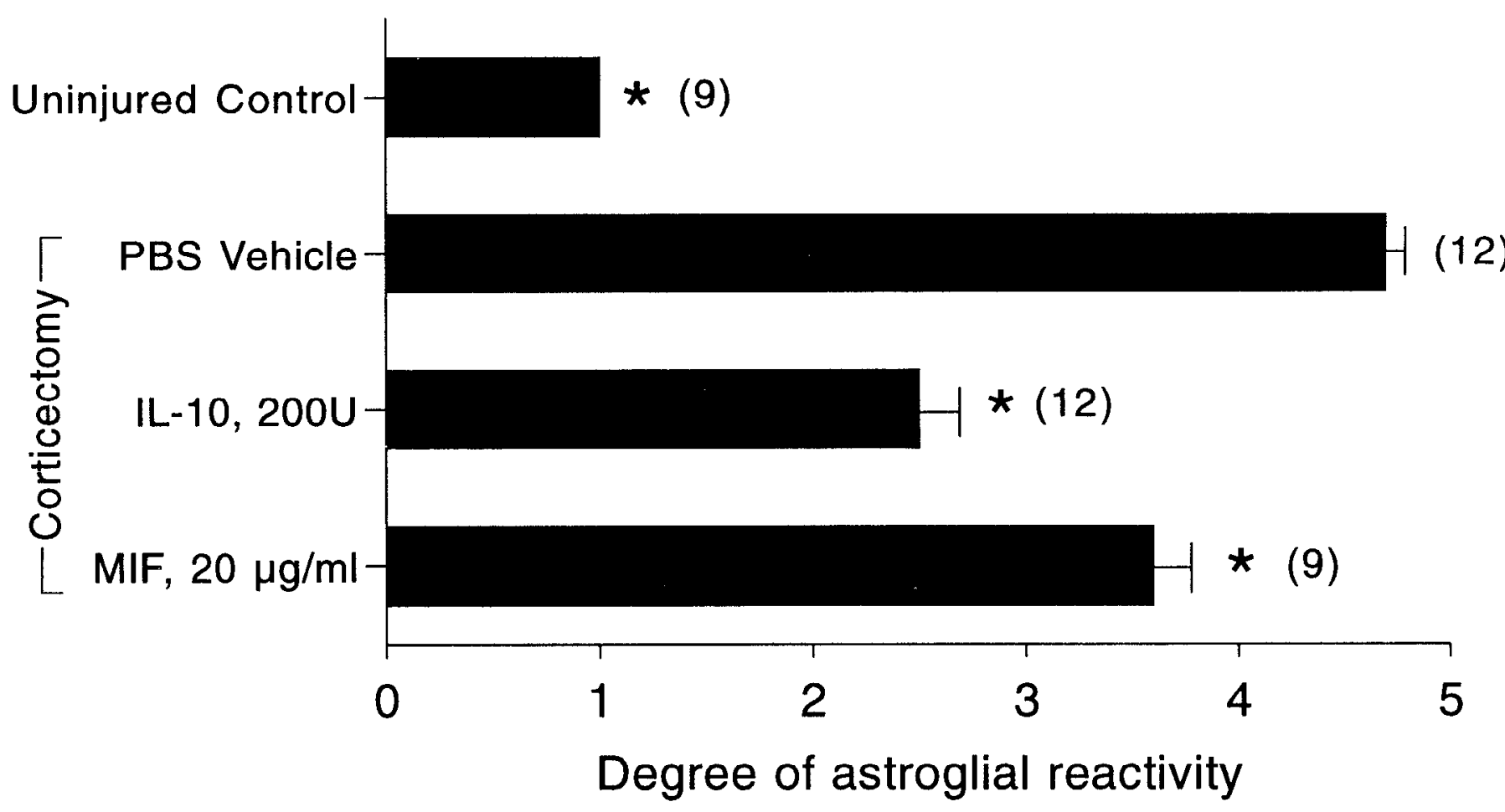

Figure 2. Cajal-stained brain sections were analyzed blind, and the extent of astroglial reactivity in the ipsilateral cortex was tabulated on a scale of 1 (no reactivity) to 5 (extensive reactivity). Values are mean \pm SEM; three brain sections per animal were analyzed; parentheses indicate the total number of sections examined. ${ }^{*} p<0.05$ compared with injured mice given PBS vehicle (one-way ANOVA with Duncan's multiple comparisons).

lowed by avidin-biotin complex reagent (Vector Laboratories, Burlingame, CA) for another $1 \mathrm{hr}$. This was followed by a biotin amplification procedure (Adams, 1992) consisting of a $10 \mathrm{~min}$ incubation with $0.2 \%$ biotinylated tyramide (Dupont, Billerica, MA) in a $0.1 \% \mathrm{H}_{2} \mathrm{O}_{2}$ solution; the time factor here was critically observed to avoid excessive background. Immunofluorescence was revealed by incubation with streptavidin conjugated to Texas Red (1:100, Dako).

\section{Assessment of in vitro astrocytic response to $I L-10$}

Proliferation and GFAP content. The procedure for the culture of neonatal astrocytes from postnatal day 1 CD1 mouse pups (Charles River Canada) and assessment of proliferation has been described in detail elsewhere (Yong et al., 1992). Culture medium was Eagle's minimum cssential medium supplemented with $5 \%$ fetal calf serum, $0.1 \%$ dextrose, and $20 \mu \mathrm{g} / \mathrm{ml}$ gentamicin. Unless otherwise stated, cells were treated once with test agents and maintained for $4 \mathrm{~d}$. Proliferation was assessed by the administration of $1 \mu \mathrm{Ci}\left[{ }^{3} \mathrm{H}\right]$ thymidine during the last 16 hir of the experiment (Yong et al., 1992). GFAP protein extraction was performed after the $4 \mathrm{~d}$ incubation period with either IL-10 $(10 \mathrm{U} / \mathrm{ml})$ or PBS and analyzed by SDS-polyacrylamide gel electrophoresis as described previously (Balasingam et al., 1994). The concentration of IL-10 used (10 $\mathrm{U} / \mathrm{ml}$ ) was 10 times higher than the in vitro $\mathrm{EC}_{50}$ concentration for costimulation (with IL-4) of MC-9 cells.

FACScanning. Astrocytic cultures treated with IL-10 or PBS for $4 \mathrm{~d}$ were trypsinized, fixed with acetic acid-ethanol (5\% glacial acetic acid: 95\% absolute ethanol, v:v), and resuspended in HHG [1 mM HEPES buffer, $2 \%$ horse serum, $10 \%$ goat serum in Hank's balanced salt solution (IIBSS)]. The cells wcre washed in HBSS and blocked with $3 \%$ chicken egg albumin before incubation with a rabbit anti-GFAP polyclonal antibody (1:100; Dako) for $30 \mathrm{~min}$. This was followed by a wash and a final incubation with secondary goat anti-rabbit immunoglobulin conjugated to fluorescein isothiocyanate (1:100; Jackson). Cells were washed twice with a solution containing HBSS and $2 \%$ fetal calf serum (FCS), followed by resuspension in FACS buffer ( $2 \%$ FCS and $0.1 \%$ sodium azide in HBSS). Intensity measurements for GFAP-IR in these cell cultures were analyzed with a Fluorescent Activated Cell Sorter flow cytometer (FACScan, Becton Dickinson, Mississauga, Ontario, Canada) using LYSYS II software (Becton Dickinson) gated for 5000 events.

\section{Reverse transcriptase-polymerase chain reaction for} $T N F-\alpha m R N A$

To demonstrate that the cytokine synthesis inhibitory factor IL-10 could indeed attenuate the production of cytokine that follows injury, the level of transcript for TNF- $\alpha$ was determined by a semiquantitative reverse transcriptase-polymerase chain reaction (RT-PCR). The oligonucleotide primers used for RT-PCR of TNF- $\alpha$ were forward primer 5 -AGCACAGAAAGCATGATCCG and reverse primer 5'-TGAAACCTCAGTAACCAGAG (Sheldon Biotechnology, Montreal, Quebec, Canada) (Renno et al., 1995). The expected PCR product is of $701 \mathrm{bp}$ and represents the entire coding sequence for murine TNF- $\alpha$. Total RNA was isolated using Trizol (Gibco, Grand Island, NY) (Balasingam et al., unpublished observations) from samples resected from around the corticectomy site $(-20 \mathrm{mg}$ wet weight). Onc microgram RNA was reversetranscribed and amplified in a single-step process (Singer-Sam et al., 1990 ) with the following modifications: $200 \mu \mathrm{M}$ deoxynucleoside triphosphates (dNTPs), $1 \mu \mathrm{M}$ primers, $2 \mathrm{mM} \mathrm{MgCl}_{2}, 2 \mathrm{U}$ of AMV RT (Gibco), 1 U of Taq polymerase (Gibco), 33 U RNA Guard (Pharmacia Biotech, Piscataway, NJ), $1 \times$ PCR buffer (Gibco), and $0.5 \mu \mathrm{Ci} / \mathrm{ml}$ $\left[\alpha^{-32} \mathrm{P}\right]$ deoxycytidine triphosphate (ICN Biochemicals, Costa Mesa, CA) in a total reaction volume of $50 \mu \mathrm{l}$. Samples were placed in a GENEAmp PCR system 9600 (Perkin-Elmer/Cetus, Norwalk, CT) at $50^{\circ} \mathrm{C}$ for $15 \mathrm{~min}$ followed sequentially by a cyclic phase at $94^{\circ} \mathrm{C}$ for $45 \mathrm{sec}, 60^{\circ} \mathrm{C}$ for $45 \mathrm{sec}$, and then $72^{\circ} \mathrm{C}$ for $1.5 \mathrm{~min}$ for a total of 26 cycles. RNA from ANA-1 cells (a mouse macrophage cell line) was coamplified and used as standard to determine the linearity of the PCR reaction. Samples were electrophoresed on a $6 \%$ nondenaturing polyacrylamide gel, dried under vacuum, visualized by autoradiography, and analyzed by ImageQuant software on a PhosphorImager system (Molecular Dynamics, Sunnyvale, CA). RTPCR for actin mRNA of each sample was also performed as described in Renno et al. (1995).

\section{RESULTS}

\section{Cajal's gold chloride sublimate method for astrocytes}

A blinded qualitative inspection of astroglial reactivity revealed the ability of IL-10 (200 U) to attenuate astroglial reactivity (Fig. 
2). Reactive astrocytes detected in the parenchyma of vehicletreated animals by this metal impregnation technique were characterized by the presence of hypertrophied cell soma and abundant processes (Figs. 1C, 3A). IL-10-treated animals revealed an attenuation in astrocyte hypertrophy and also had reduced numbers of reactive astrocyles (Fig. $3 B$ ).

\section{GFAP-IR}

We proceeded to investigate whether there was a dose-dependent relationship to the effects of IL-10 in attenuating astroglial reactivity. GFAP-IR was chosen as a read-out to use a second detection system for astroglial reactivity. Furthermore, GFAP-IR is normally absent in the normal murine cortex (Bignami and Dahl, 1976; Yong and Balasingam, 1995), although this gray matter area contains protoplasmic astrocytes and GFAP.

In a blinded analysis of GFAP-IR, vehicle-treated controls had the largest degree of astroglial reactivity (Fig. 4), in accordance with results obtained by the Cajal gold chloride sublimate technique. The effect of IL-10 on astroglial reactivity was dosedependent with significant inhibition at the higher doses used (Fig. 4).

A striking observation by GFAP-IR is the presence of reactive astrocytes that border the lesion in vehicle-treated controls (Fig. $3 C$ ) but not in IL-10 treated animals (Fig. $3 D$ ). The non-GFAP-IR rim of tissue, present immediately adjacent to the cortical wound in IL-10-treated animals, extended from the glial limitans to the corpus callosum (Fig. 5). This rim was seen in 8 of 10 IL-10treated $(200 \mathrm{U})$ animals, and in 0 of 10 vehicle-treated controls ( $p<0.001$, Student's $t$ test).

The presence of a non-GFAP-IR rim in IL-10-treated animals, but not in controls, could be indicative of a suppression of astroglial reactivity by IL- 10 close to the site of application, because nonreactive astrocytes in the cortex are normally not GFAP-IR. Alternatively, the rim could represent necrotic tissue. To address the latter, paraffin-embedded sections were stained for GFAP and revealed by AEC chromagen, and then counterstained with hematoxylin. Vehicle-treated controls showed the presence of viable tissue and GFAP-IR reactive astrocytes in areas adjacent to the lesion (Fig. 3E). Similarly, the lesion-bordering tissue of IL-10 animals was viable; however, in contrast to vehicle-treated controls, there were significantly fewer GFAP-IR astrocytes in IL-10treated animals (Fig. 3F). Another revelation using the GFAPAEC method was the higher background of brown GFAP reaction product in PBS animals versus IL-10 animals, indicative of greater astroglial reactivity in the former. That this was not the result of differences in staining conditions was demonstrated by the similar staining intensity of GFAP, and the counterstain, in both groups in the unaffected contralateral corpus callosum (see inserts in Fig. $3 E, F)$.

The extent of astroglial reactivity after either vehicle or IL-10
(200 U) treatment was quantitated by measuring the total number of GFAP-IR astrocytes present on each side of the cortical lesion. This computation confirmed the qualitative results that IL-10 attenuated astroglial reactivity; indeed, IL-10 reduced the number of reactive astrocytes per $20 \mu \mathrm{m}$ brain section by $60 \%$ when compared with vehicle controls (Table 1).

\section{Mac-1 immunohistochemistry}

The Mac-1 antibody marks the type 3 complement receptor (CR3) (Springer et al., 1979; Beller et al., 1982), which functions in the phagocytosis of opsonized particles. CR3 is widely expressed on cells belonging to the mononuclear phagocyte system. Comparisons between vehicle (Fig. $3 G$ ) and IL-10 (Fig. $3 H$ ) brains showed that Mac-1-positive cells were more densely packed and more intensely stained around the lesion site in controls than in the IL-10 brains, indicative of a suppression of macrophage/ microglial reactivity in IL-10 animals. The results were reproduced in multiple sections taken from three animals in each group.

\section{IL-10 did not directly alter astrocyte function in vitro}

Astrocytes have receptors for a large number of cytokines (e.g., IL-1, Il-6, IL-7, IFN- $\alpha / \beta$, IFN- $\gamma$, TNF- $\alpha$ ) (Rubio and de Felipe, 1991; Ban et al., 1993; Sawada et al., 1993; Tada et al., 1994; Aranguez et al., 1995), including IL-10 (Mizuno et al., 1994), and can be directly affected by these cytokines. Thus, TNF- $\alpha$, IL-1, and IFN- $\gamma$ can alter the proliferation rate (Giulian and Lachman, 1985; Barna et al., 1990; Selmaj et al., 1990; Yong et al., 1992; Balasingam et al., 1994) and GFAP mRNA transcription (Oh et al., 1993) of astrocytes in vitro. To determine whether the effects of IL-10 on astrocytic reactivity in vivo could be because of a direct action on astrocytes, we determined whether IL-10 could modulate astroglial activity using purified murine astrocytes in culture.

Measurements of $\left[{ }^{3} \mathrm{H}\right]$ thymidine incorporation revealed the inability of IL-10 to affect astrocyte proliferation when compared with its PBS vehicle (Fig. $6 B$ ). Similarly, there was no change in GFAP content after IL-10 treatment of astrocytic cultures for up to $4 \mathrm{~d}$ (Fig. 6C). Finally, FACScan analysis revealed no difference in intensity levels for cytoplasmic GFAP-IR between vehicle and IL-10 cultures (Fig. $6 A$ ).

If the in vivo results were the consequence of the sustained release of IL-10 into the damaged tissue over $4 \mathrm{~d}$, then it is possible that this continual presence of IL-10 may not be reflected in culture if IL-10 were less stable in vitro. Thus, to obviate the possibility that the lack of effects of IL-10 on astrocytes in vitro were attributable to its decreased stability, cultured astrocytes were treated with fresh IL-10 daily for $4 \mathrm{~d}$ and then analyzed for GFAP-IR (by flow cytometry) and proliferation rate. Despite the daily treatment, however, astrocytes in culture did not alter their GFAP-IR (mean intensity fluorescence of $565 \pm 105$ in controls vs

\footnotetext{
Figure 3. Cortical brain sections of corticectomy animals treated with PBS vehicle $(A, C, E, G)$ or $200 \mathrm{U}$ of IL-10 $(B, D, F, H)$; the region where the photograph was taken is illustrated by the dot in each diagram inside cach frame. Cajal's gold sublimate technique (Magnification, $400 \times)$ : $A$ shows increased number and hypertrophism of reactive astrocytes in vehicle-treated animals, and $B$ shows decreased number of and less hypertrophied reactive astrocytes in IL-10 mice. Fluorescent GFAP-IR $(100 \times): C$ demonstrates the presence of reactive astrocytes that abut the lesion border in vehicle-treated animals, and $D$ displays a paucity of reactive astrocytes (indicated with arrows) at sites that border the lesion of IL-10 animals. Nonfluorescent GFAP-IR revealed by AEC chromagen and counterstained with hematoxylin $(300 \times): E$ indicates the presence of viable tissue and GFAP-IR-reactive astrocytes at lesion-bordering sites of vehicle-treated animals, and $F$ shows the presence of viable tissue and a paucity of GFAP-IR astrocytes at similar sites of IL-10 subjects. The corresponding unaffected contralateral corpus callosum is shown as inserts to demonstrate that the differential staining and counterstaining between frames $E$ and $F$ is not because of different staining conditions. Mac- 1 immunohistochemistry (400×): $G$ displays the presence of intensely stained and dense microglia/macrophages at the lesion site of vehicle-treated animals compared with similar area in IL-10 brains $(H)$; yellow denotes areas of most intense fluorescence. The intensity of Mac-1 staining at the lesion site of each brain section, as assessed by confocal microscopy, has been normalized to Mac-1 fluorescence in the contralateral, noninjured cortex to allow for comparisons between sections.
} 


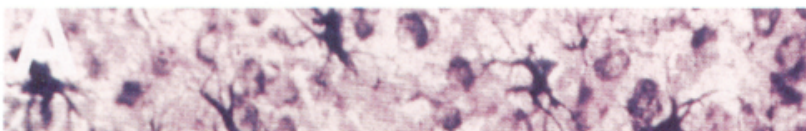

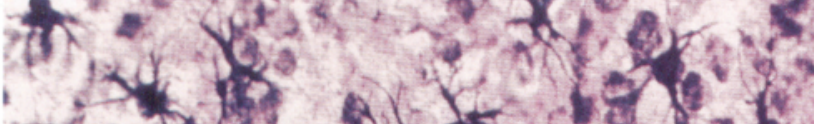

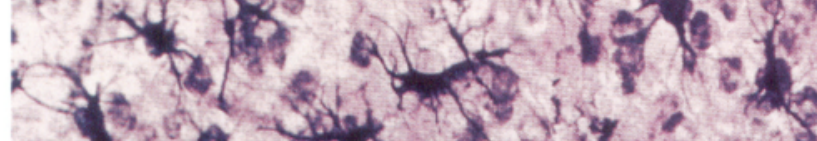

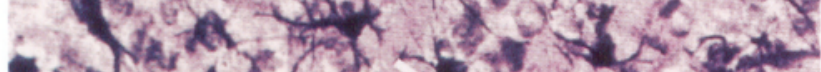

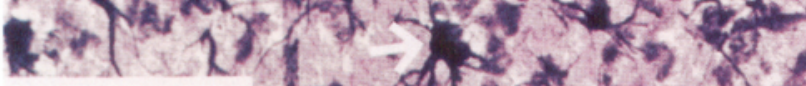

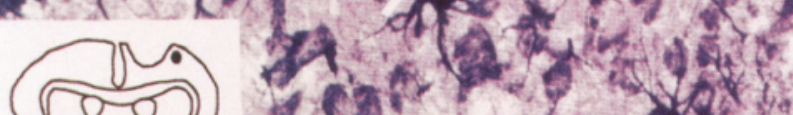

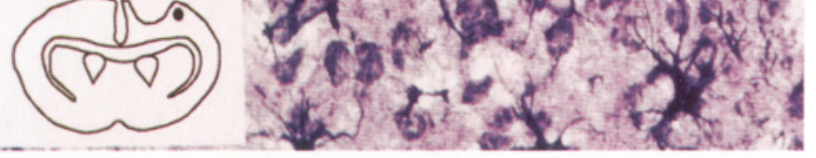

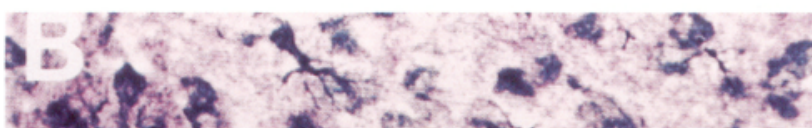

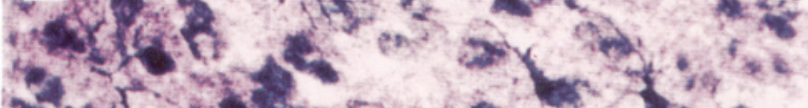

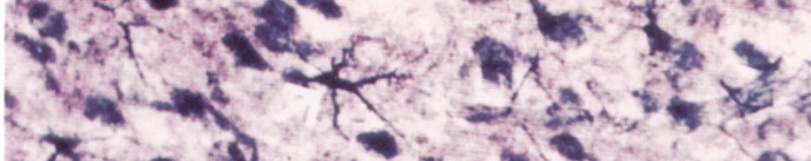

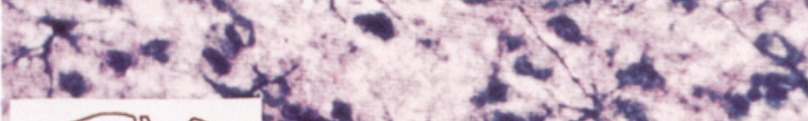
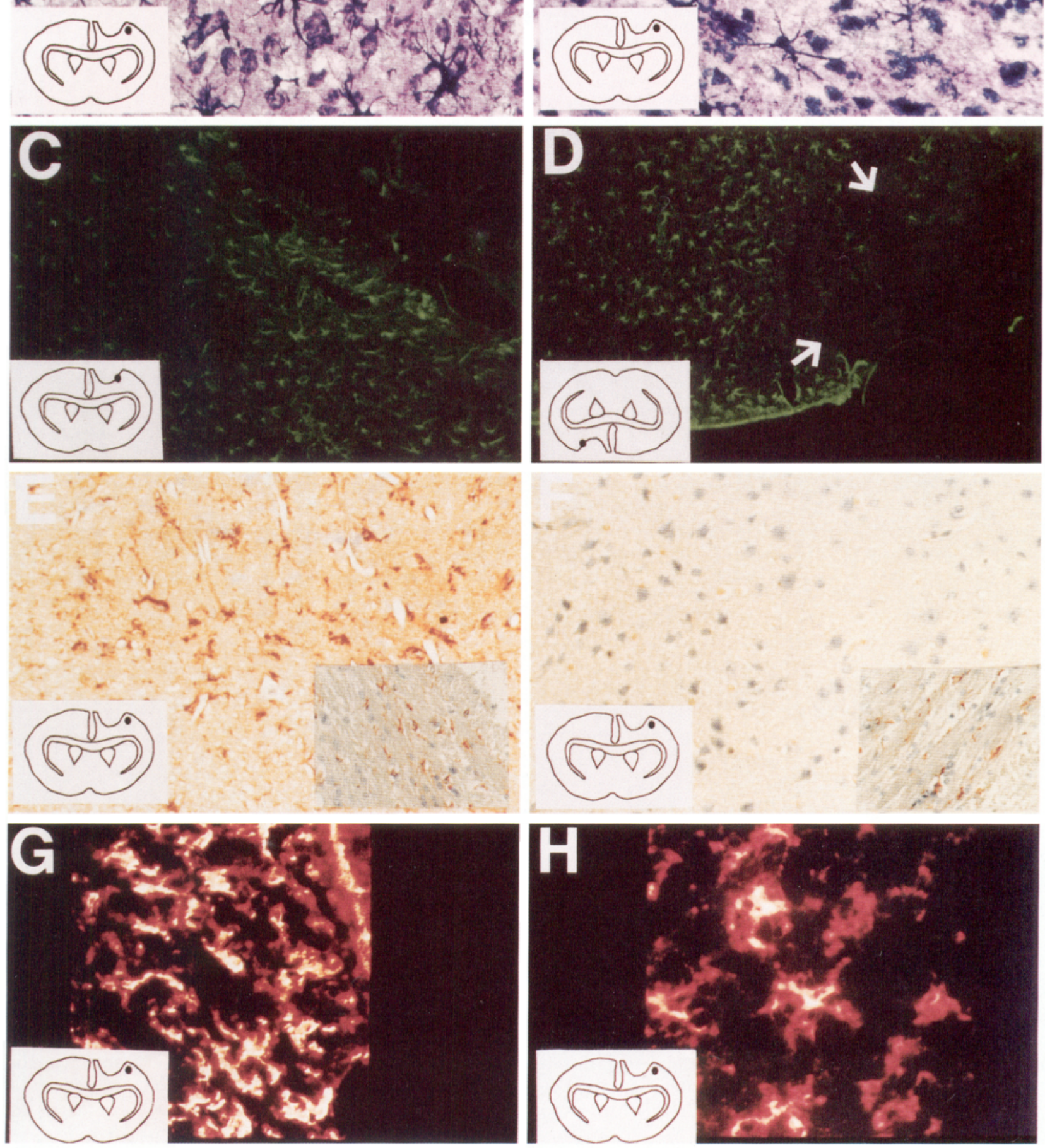


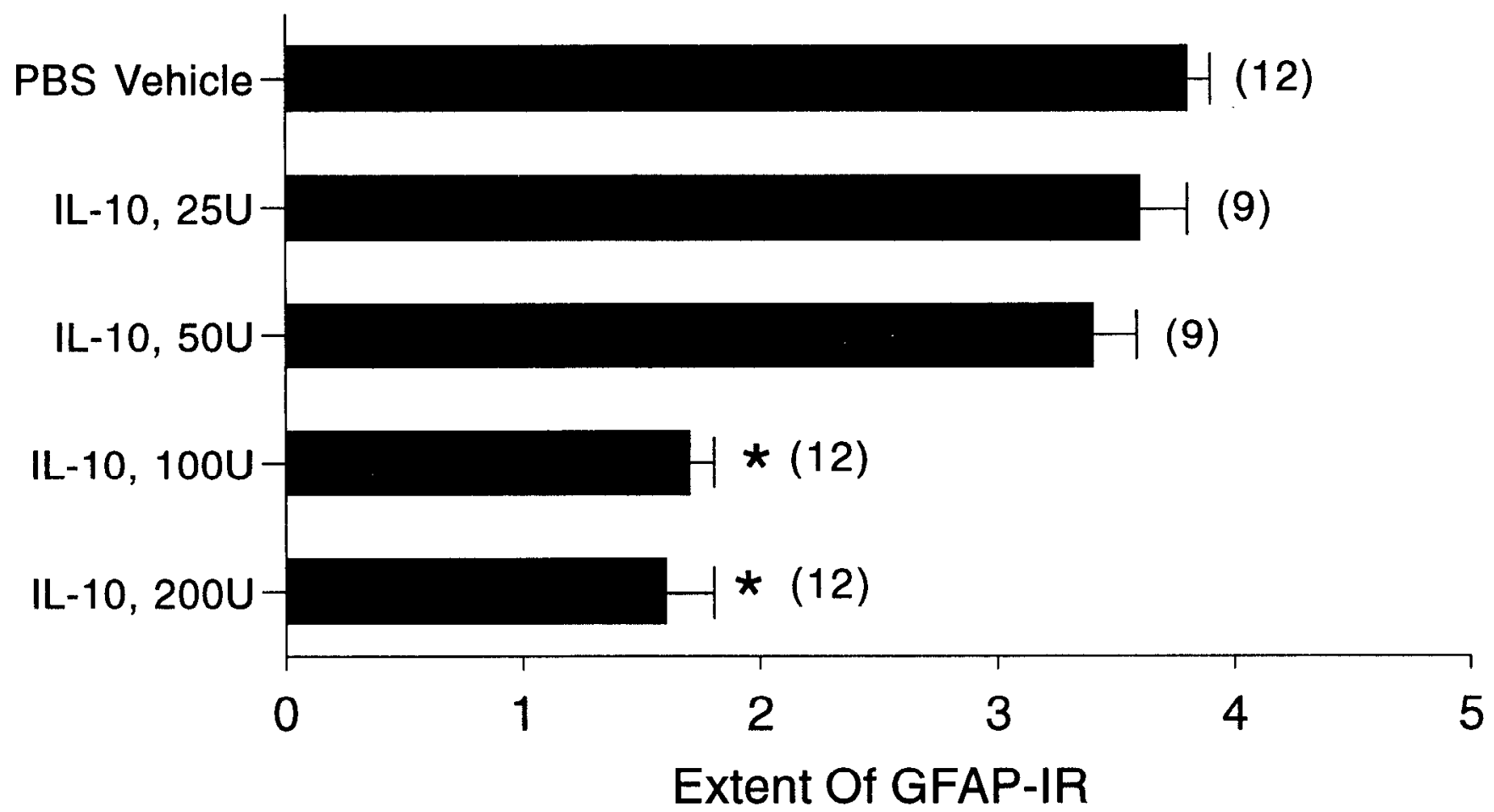

Figure 4. Brain sections were analyzed blind, and the extent of astroglial reactivity in the ipsilateral cortex was tabulated on a scale of 1 (no reactivity) to 4 (extensive reactivity). Values are mean \pm SEM; three brain sections per animal were analyzed; parentheses indicate the total number of sections examined. ${ }^{*} p<0.05$ compared with PBS-vehicle (one-way ANOVA with Duncan's multiple comparisons).

$581 \pm 183$ in IL-10, mean + SEM, $n$ of 3 each) or proliferation rate $(5261 \pm 329 \mathrm{cpm}$ in controls vs $5741 \pm 241 \mathrm{cpm}$ in IL-10, mean $\pm \mathrm{SEM}, n$ of 4 each) in response to IL- 10 .

\section{Macrophage inhibitory factor also decreases astroglial reactivity}

To address the role of macrophage/microglia in astroglial reactivity further, another agent known to inhibit macrophage function was used. This agent, macrophage inhibitory factor (MIF), is an immunoglobulin derived tripeptide Thr-Lys-Pro (Tuftsin fragment 1-3, Sigma, St. Louis, MO) that has in vitro inhibitory properties on the release of lysosomal enzymes, phagocytosis, and the production of superoxide anion by macrophage and monocytes (Auriault et al., 1983). In vivo, the inhibition of microglial activity by MIF has been shown to influence the elimination of axotomized ganglion cells (Thanos et al., 1993).

Our investigation revealed that the single application of $500 \mu \mathrm{M}$ MIF significantly reduced astroglial reactivity when compared with vehicle-treated controls (Fig. 2). However, the effect of MIF was not as marked as that of IL- 10 .

\section{RT-PCR analyses for TNF- $\alpha$ mRNA levels}

IL-10 is a cytokine synthesis inhibitor of cells that include macrophages/microglia. To verify that the effects of IL-10 on the attenuation of astroglial reactivity was via the inhibition of cytokine synthesis, areas surrounding the corticectomy site were resected out and subjected to RT-PCR analyses for mRNA levels of a macrophage-derived cytokine, TNF- $\alpha$.

Figure 7 demonstrates that the TNF- $\alpha$ mRNA level of noninjured animals, using a 26 cycle PCR, is near the limit of detection. However, by $12 \mathrm{hr}$ after injury (the earliest time point examined), TNF- $\alpha$ transcripts were significantly increased. The administration of IL-10 attenuated by $30-40 \%$ the rise in TNF- $\alpha$ levels produced by injury; this was statistically significant at $24 \mathrm{hr}$ after the application of IL-10. Thus, IL-10 in vivo reduced the injuryelicited elevation of the cytokine TNF- $\alpha$.

To verify that the decrease in TNF- $\alpha$ transcript levels by IL-10 was not attributable to sampling error, RT-PCR analyses were performed for actin transcripts in the same individual specimens analyzed for TNF- $\alpha$. PhosphorImager reading (mean \pm SEM) for uninjured controls was $2836635 \pm 257299$ ( $n$ of 5); for PBS vehicle was $2782423 \pm 86080$ ( $n$ of 4 ); and for IL-10 was $2719213 \pm$ 120966 ( $n$ of $5 ; 98 \%$ of PBS vehicle group).

\section{DISCUSSION}

The activation of intrinsic microglia and the recruitment of bloodderived macrophages to the lesion site are among the earliest cellular responses that follow anisomorphic injuries to the adult CNS (Kitamura et al., 1972; Tsuchihushi et al., 1981; Boya et al., 1986; Giulian, 1987; Moorshead and van der Kooy, 1990; Leong and Ling, 1992; Balasingam et al., unpublished observations). Because of the lack of markers to differentiate between microglia and macrophages, these mononuclear phagocytes are often collectively referred to as macrophages/microglia. Guilian and colleagues (1989) have used chloroquine and colchicine to suppress the function of invading macrophage/microglia, and have reported a reduction of astroglial reactivity after traumatic injury. Similar suppression of macrophage/microglia activity also prevented the deterioration of hindlimb motor function after ischemic injury to the spinal cord (Giulian and Robertson, 1990). Because chloroquine and colchicine are nonspecific inhibitors of macrophage/microglia, it was reasoned that more specific inhibitors of macrophage/microglia would provide a more effective means to attenuate the development of reactive astrocytes and reveal the role of macrophage/microglia in astroglial reactivity. In 

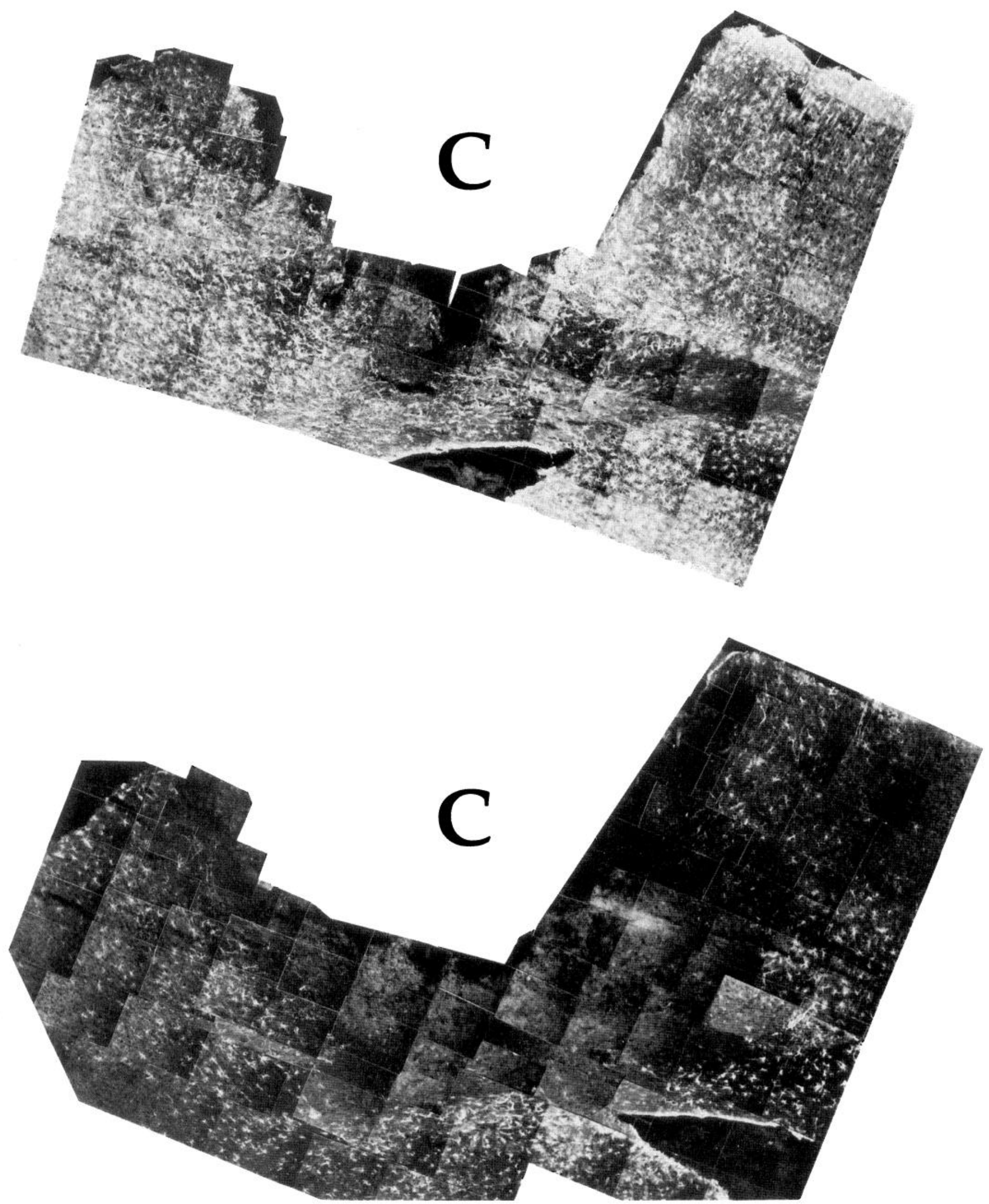

Figure 5. Montage of photographs of GFAP immunofluorescence taken around the lesioned cavity $(C)$ of PBS vehicle (top) or IL-10 animals (bottom). For each montage, the upper margin is the dorsal glia limitans and the lower margin is the corpus callosum; part of the lateral ventricle can be seen as a hole at the bottom of each montage, surrounded by a lining of GFAP-positive ependymal cells. Note that a significant area of the IL-10 brain contains nonreactive astrocytes; this is especially evident in the penumbra rim area that surrounds the cavity site. 


$\begin{aligned} & \text { Table 1. IL-10 decreases the number of reactive astrocytes in murine } \\
& \text { cortex }\end{aligned}$
\begin{tabular}{lll} 
Treatment & \# of sections/\# of mice & $\begin{array}{l}\text { \# of GFAP-IR cells per } \\
20 \mu \mathrm{m} \text { brain section }\end{array}$ \\
\hline PBS Vehicle & $15 / 5$ & $927 \pm 55$ \\
IL-10, 200 U & $18 / 6$ & $385 \pm 20^{*}$
\end{tabular}

Confocal microscopy was used to analyze GFAP-IR in the murine cortex as described previously (Balasingam et al., 1994). Images compiled from the entire ipsilateral coronal section were printed and then reconstructed on paper to obtain the entire ipsilateral coronal section. From the reconstructed images (magnified $\sim 1000 \times$ ), the number of reactive astrocytes (GFAP-IR) in the cortex was manually counted. Values displayed above are mean \pm SEM of the total number of reactive astrocytes per brain section in the cortex; three brain sections per animal, taken from the corticectomy region, were analyzed. ${ }^{*} p<0.001$ compared with PBS vehicle (unpaired Student's $t$ test).

this report, we have used IL-10, a potent cytokine synthesis inhibitor, as an immunosuppressant to inhibit the function of macrophages/microglia after an adult aspiration corticectomy model in an attempt to attenuate astrocyte reactivity. Such studies would improve the understanding of mechanisms that produce astroglial reactivity and would also provide the means to examine the neurotrophic consequences of the reactive astrocyte.

The results of this report demonstrate that IL-10 decreased astroglial reactivity in a dose-related manner (Fig. 4). In this regard, there was a decrease in both the number (Table 1) and the hypertrophic state of reactive astrocytes (Fig. 3). Immediately adjacent to the site of IL-10 application, viable astrocytes were nonreactive in contrast to those in vehicle-treated animals, suggesting that IL-10 has ablated the evolution of astrogliosis in its immediate vicinity. Farther away from the site of IL-10 administration, reactive astrocytes could be found (Fig. 5), probably reflecting the decreased diffusability of IL-10 to these regions.

The reduction in astroglial reactivity is unlikely to be attributable to a direct effect of IL-10 on astrocytes, because IL-10 had no effect on astrocyte cultures in vitro in terms of their proliferation, GFAP content, or GFAP-IR (Fig. 6). What then could be the mechanisms of IL-10 in attenuating astroglial reactivity? To address this, it would be instructive to review relevant aspects of IL-10 biology. IL-10 is a product of B cells, TH0 and TH2 cells, and of macrophages late in their activation (Moore et al., 1990; Mosmann et al., 1990; O'Garra et al., 1990; de Waal Malefyt et al., 1991a). The immunosuppressive effect of IL-10 can be mediated via several avenues: first, IL-10 diminishes the antigen-presenting capacity of monocytes/macrophages to T lymphocytes (Fiorentino et al., 1991b) by inhibiting both the constitutive and induced expression of MHC class II antigens (de Waal Malefyt et al., 1991b; Frei et al., 1994; Rott et al., 1994). Second, IL-10 impairs the ability of monocytes/macrophages to provide costimulatory signals for activation of resting T cells in vitro. Ding and colleagues $(1992,1993)$ have demonstrated that this impairment is mediated by the suppression of a macrophage membrane-bound antigen, B7/BB1, a costimulator of $\mathrm{T}$ cell antigens CD28 and CTLA-4. Third, activated monocytes/macrophages can also produce IL-8 (Yoshimura et al., 1987; Sylvester et al., 1990) and IL-12 (Kobayashi et al., 1989; D'Andrea et al., 1992), the function of which is inhibitable by IL-10 (Tripp et al., 1993; Mosmann, 1994). IL-8 is a chemotactic factor for neutrophils (Baggiolini et al., 1989) and T lymphocytes (Larsen et al., 1989). The suppression of this chemoattractant activity would decrease the recruitment of inflammatory cells to the lesion site. IL-12, or natural killer (NK) cell stimulatory factor, is a strong inducer of IFN- $\gamma$ production by
A. GFAP-IR by flow cytometry
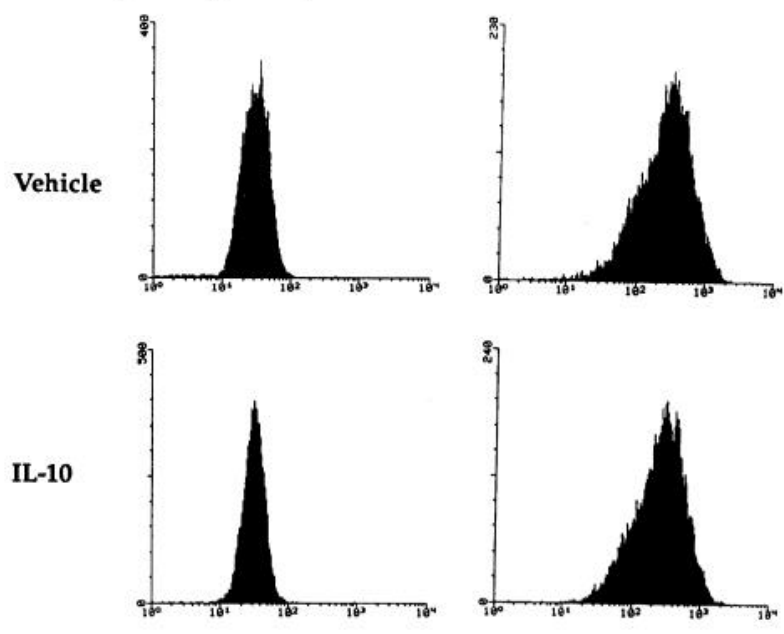

\section{B. Proliferation Rate (cpm)}

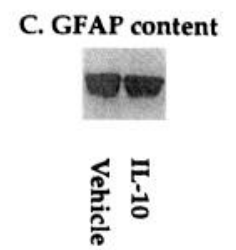

Figure 6. Effects of IL-10 on astrocytes in vitro. In $A$, flow cytometer analysis revealed no differences in intensity levels for GFAP-IR between either Vehicle or $I L-10$ treatment. The left panel of each treatment is the fluorescent intensity of cells stained with secondary antibody alone, and the right panels are of cells labeled for GFAP followed by the secondary antibody. The mean intensity fluorescence for GFAP after IL-10 in the example shown ( $2 \mathrm{~d}$ treatment) is 322.6 , whereas that for vehicle is 342.8 . This lack of change was also observed for $4 \mathrm{~d}$ of treatment, and was demonstrated for two other sets of cultures. In $B$, the proliferation rate of astrocytes (mean \pm SEM) did not differ after either vehicle or IL-10 treatment for 2 or $4 \mathrm{~d}$ as determined by $\left[{ }^{3} \mathrm{H}\right]$ thymidine incorporation; $\mathrm{cpm}$, Counts per min. The proliferation results are reproduced in four separate experiments. The lower rate of proliferation at $4 \mathrm{~d}$ compared with $2 \mathrm{~d}$ in both the vehicle and IL-10 groups is related to the attainment of confluency at $4 \mathrm{~d}$. In $C$, a representative GFAP Western (band appears at 49 $\mathrm{kDa}$ ) of $15 \mu \mathrm{g}$ of total cell extract is shown for cells treated for $2 \mathrm{~d}$ with IL-10 (PhosphorImager volume of 406,203) or PBS (PhosphorImager volume of 419,485$)$. This lack of change was reproduced in three other sets of cultures, after 2 or $4 \mathrm{~d}$ of treatment.

NK and T cells (Chan et al., 1991). Thus, the inhibition of IL-12 synthesis/function can contribute to the attenuation of an immune cascade. Finally, as stated earlier, IL-10 is a potent inhibitor of the synthesis of several cytokines by leukocytes.

Several lines of evidence would suggest that the effects of IL-10 in attenuating astroglial reactivity is via the inhibition of cytokine production by macrophages/microglia. First, macrophage/microglia-derived cytokines alone (IL-1, TNF- $\alpha$ ) can convert the degree of astrogliosis in neonatal animals after trauma from minimal to extensive (Balasingam et al., 1994). In adult animals, these cytokines enhance the astrogliosis that is the usual result of CNS injury (Giulian et al., 1988; Brosnan et al., 1989); IFN- $\gamma$, a potent activator of macrophage/microglia, also increases the extent of astroglial reactivity in adult animals (Yong et al., 1991). Second, another agent known to decrease macrophage/ microglia function, MIF, also reduced astroglial reactivity (Fig. 2). Third, we demonstrate that the level of mRNA for TNF- $\alpha$, a cytokine that can induce astroglial reactivity, is indeed reduced in 


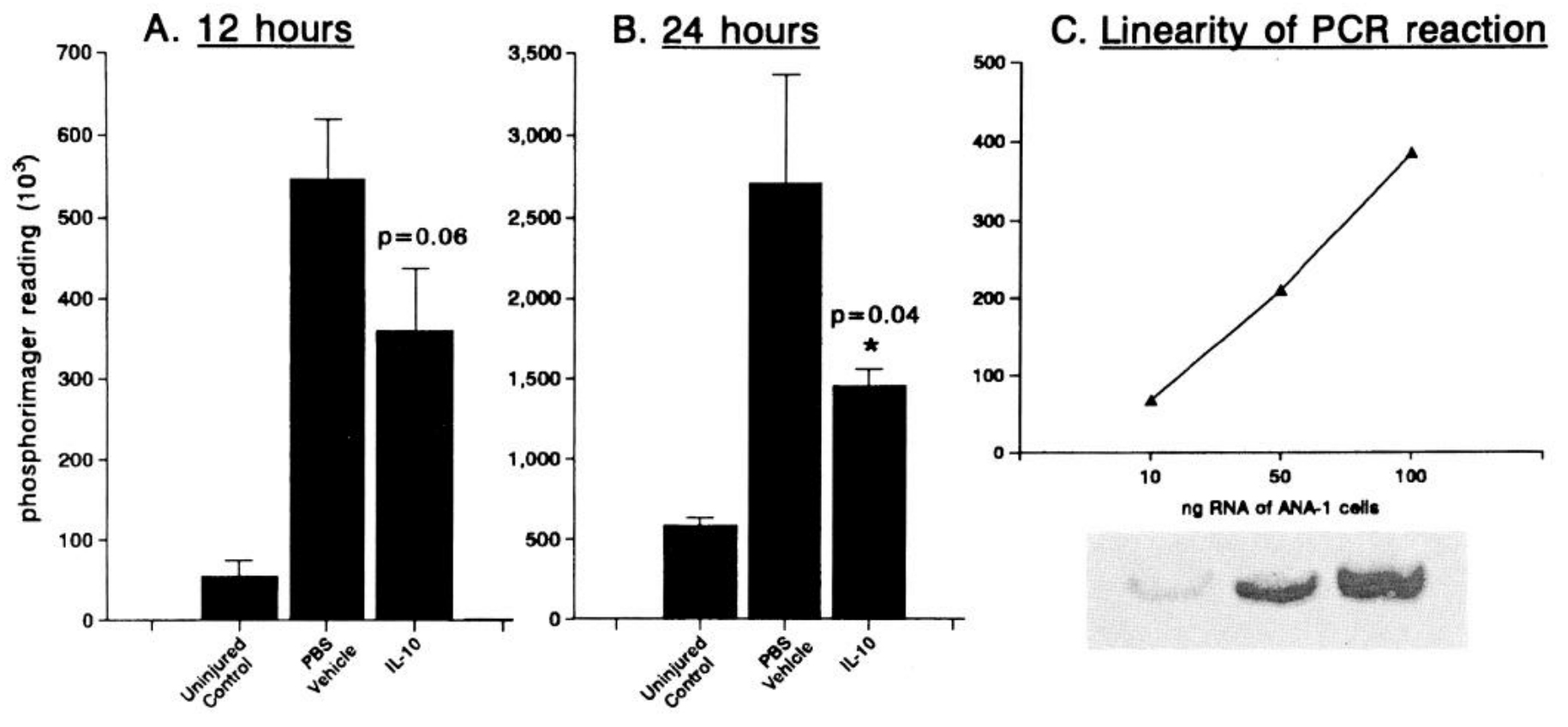

\section{PCR products at 24 hours after injury}
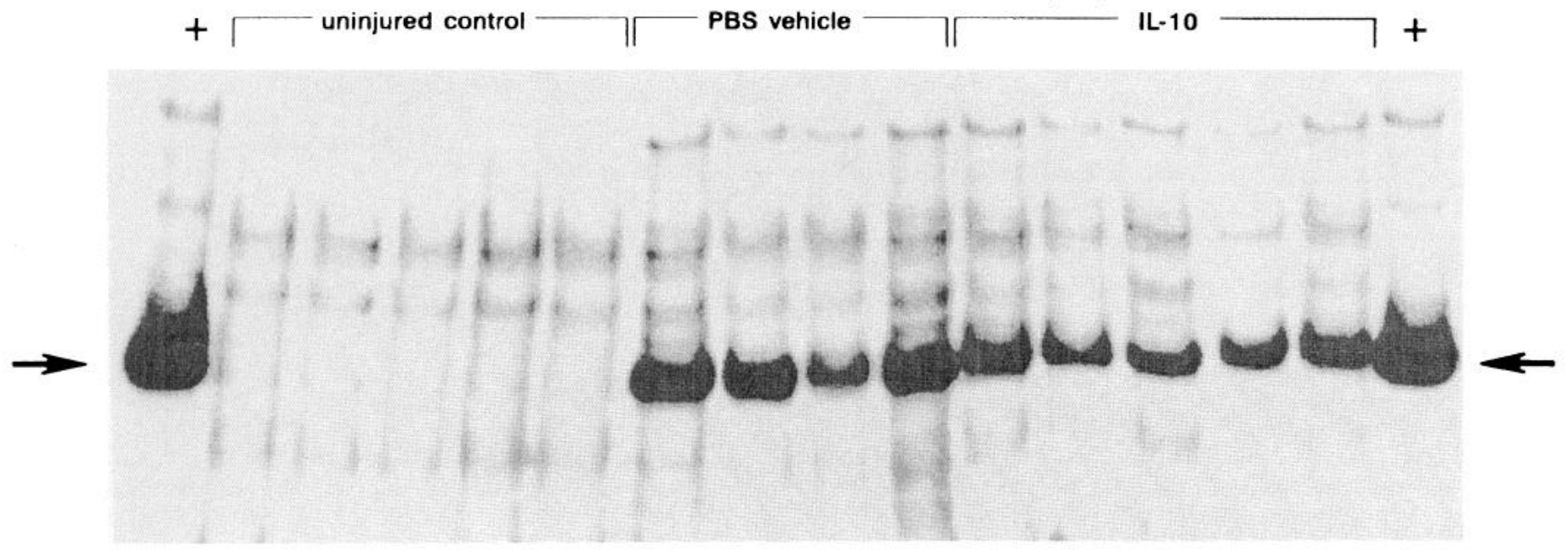

Figure 7. Semiquantitative RT-PCR analyses for TNF mRNA in the adult mouse brain. Brain tissue surrounding the corticectomy site was dissected out ( $\sim 20 \mathrm{mg}$ wet weight), placed in Trizol (Gibco), and total RNA extracted as per the manufacturer's instructions. RNA samples were then subjected to RT-PCR as described in the text. $A$ and $B$ demonstrate that TNF $\alpha$ signals increase rapidly after injury; this increase can be attenuated by IL-10. $p$ values refer to Student's $t$ test comparisons between IL-10 and PBS controls. In $A$ and $B$, each bar is mean \pm SEM of four or five samples. Values are in PhosphorImager units; the difference in the PhosphorImager scale for $A, B$, and $C$ is attributable to the different background in each case, each panel representing a separate gel. In $C$, the linearity of the PCR reaction at 26 cycles is confirmed using ANA-1 cells, a mouse macrophage cell line. In $D$, the PCR reaction products are shown using samples collected at $24 \mathrm{hr}$ after injury. The $701 \mathrm{bp}$ TNF $\alpha$ cDNA product is indicated by the arrow; + lanes at each end of the gel represent ANA-1 samples, which were used as positive controls for RT-PCR.

the extracts of brain that surround the injury site of IL-10 mice (Fig. 7). Finally, IL-10 treatment decreased the density and intensity of Mac-1-positive macrophages/microglia (Fig. 3), suggesting the reduced function of this cell type. However, we should caution that the apparent reduction of the density of Mac-1-positive cells could be the result of IL-10 decreasing the influx of macrophages into the lesioned area, rather than an effect of IL-10 in reducing the activation state of existent microglia. To resolve these possibilities, one would need to show that the number of macrophages/ microglia per unit area is the same in both the vehicle and IL-10 groups, but that their Mac-1 staining intensity is different; however, we have been unable to reliably count the number of cells per unit area because many of the microglia/macrophages, espe- cially in the vehicle-treated brains, were clumped together, rather than situated distinctly apart.

It should be noted that besides microglia/macrophages, other neural cells are also potential sources of TNF- $\alpha$ both in vitro and in vivo (for review, see Yong, 1996), and these include reports of neurons being TNF- $\alpha$ immunoreactive in normal murine brains as well as after CNS injury (Breder et al., 1993; Tchelingerian et al., 1993). It would be of interest to determine whether the neuronal or astroglial production of TNF- $\alpha$ could also be modulated by IL-10 after insults to the CNS.

Previously, the consequences of astroglial reactivity were thought to be undesirable, as glial "scars" were found to inhibit axonal growth or regeneration (Reier et al., 1983; Liuzzi and 
Lasek, 1987), interfere with remyelination (Raine and Bornstein, 1970), or be the sites of electrical instability and epilepsy (Pollen and Trachtenberg, 1970). Although these detriments are possible consequences of the long-term glial "scars," more recent studies indicate that the process of astroglial reactivity, especially in the early stages, may actually represent an attempt by astrocytes to promote recovery. This concept has evolved from studies (for review, see Yong, 1996) that indicate that cultured astrocytes synthesize a range of neurotrophic factors; that astrocytes are conducive substrates for the survival and growth of neurons in vitro; that neurotrophic factors are produced around the locus of a lesion and that the source of these appears to be reactive astrocytes; and in vivo data that astrocytes can promote regeneration under very specific circumstances. To resolve the dichotomy of glial "scars" being impediments to recovery and the numerous neurotrophic properties of astrocytes, the control of astroglial reactivity that follows injury would be beneficial. Thus, the finding in this study that IL-10 can attenuate astroglial reactivity should add to the efforts to define the functions of reactive astrocytes.

In conclusion, the results show that astroglial reactivity can be attenuated by the administration of IL-10, which likely acts by inhibiting the production of cytokines by macrophages/microglia. The findings point to the importance of immune-mediated mechanisms to brain pathology in general and to astroglial reactivity in particular. The ability to manipulate the extent of astrogliosis can now provide a means of addressing the neurotrophic or inhibitory role of reactive astrocytes in neurological recovery.

\section{REFERENCES}

Adams IC (1992) Biotin amplification of biotin and horseradish peroxidase signals in histochemical stains. $J$ Histochem Cytochem 40:1457-1463.

Aranguez I, Torres C, Rubio N (1995) The receptor for tumor necrosis factor on murine astrocytes: characterization, intercellular degradation, and regulation by cytokines and Theiler's murine encephalomyelitis virus. Glia 13:185-194.

Auriault C, Joseph M, Tartar A, Capron A (1983) Characterization and synthesis of a macrophage inhibitory peptide from the second constant domain of human immunoglobulin G. FEBS Lett 153:11-15.

Baggiolini M, Walz A, Kunkel SK (1989) Neutrophil-activating peptide1/interleukin 8 , a novel cytokine that activates neutrophils. J Clin Invest 84:1045-1049.

Balasingam V, Tejada-Berges T, Wright E, Bouckova R, Yong VW (1991) Reactive astrogliosis in the neonatal mouse brain and its modulation by cytokines. J Neurosci 14:846-856.

Ban EM, Sarlieve LL, Haour FG (1993) Interleukin-1 binding sites on astrocytes. Neuroscience 52:725-733.

Barna BP, Estes ML, Jacobs BS, Hudson S, Ransohoff RM (1990) Human astrocytes proliferate in response to tumor necrosis factor alpha. J Neuroimmunol 30:239-243.

Barrett CP, Donati EJ, Guth L (1984) Differences between adult and neonatal rats in their astroglial response to spinal injury. Exp Neurol 84:374-385.

Beller DI, Springer TA, Schreiber RD (1982) Anti Mac-1 inhibits the mouse and human type three complement receptor. J Exp Med 156:1000-1009.

Berry M, Maxwell WL, Logan A, Mathewson A, McConnell P, Ashburst DE, Thomas GII (1983) Deposition of scar tissuc in the central nervous system. Acta Neurochir Suppl (Wien) 32:31-53.

Bignami A, Dahl D (1976) The astroglial response to stabbing: immunofluorescence studies with antibodies to astrocyte-specific protein (GFA) in mammalian and submammalian vertebrates. Neuropath Appl Neurobiol 2:99-110.

Bogdan C, Paik J, Vodovotz Y, Nathan C (1991) Macrophage deactivation by interleukin 10. J Exp Med 174:1549-1555.

Boya J, Calvo J, Carbonell AL, Garcia-Maurino E (1986) Nature of macrophages in rat brain: a histochemical study. Acta Anat (Basel) $127: 142-145$.
Breder CD, Tsujimoto M, Terano Y, Scott DW, Saper CB (1993) Distribution and characterization of tumor necrosis factor- $\alpha$-like immunoreactivity in the murine central nervous system. J Comp Neurol 337:543.

Brosnan CF, Litwak MS, Schroeder CE, Selmaj K, Raine CS, Arezzo JC (1989) Preliminary studies of cytokine-induced functional effects on the visual pathways in the rabbit. $\mathrm{J}$ Neuroimmunol 25:227-239.

Chan SH, Perussia B, Gupta JW, Kobayashi M, Pospisil M, Young HA, Wolf SA, Young D, Clark SC, Trinchieri G (1991) Induction of IFN- $\gamma$ production by NK cell stimulatory factor (NKSF): characterization of the responder cells synergy with other inducers. $\mathbf{J} \operatorname{Exp}$ Med 173:869-879.

da Cunha A, Jefferson JJ, Tyor WR, Glass JD, Jannotta FS, Vitkovic L (1993) Control of astrogliosis by interleukin-1 and transforming growth factor- $\beta 1$ in human brain. Brain Res 631:39-45.

D'Andrea A, Rengaraju M, Valiante NM, Chehini J, Kubin M, Aste M, Chan SH, Kobayashi M, Young D, Nickbarg E (1992) Production of natural killer cell stimulatory factor (NKSF/IL-12) by peripheral blood mononuclear cells. J Exp Med 176:1387-1398.

D'Andrea A, Aste-Amezaga M, Valiante NM, Xiaojing M, Kubin M,

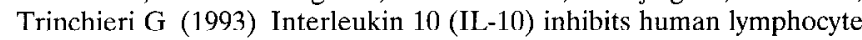
interferon- $\gamma$ production by suppressing natural killer cell stimulatory factor/IL-12 synthesis in accessory cells. J Exp Med 178:1041-1048.

de Waal Malefyt R, Abrams J, Bennett B, Figdor CG, de Wries JE (1991a) Interleukin 10 (IL-10) inhibits cytokine synthesis by human monocytes: an autoregulatory role of IL-10 produced by monocytes. J Exp Med 174:1209-1220.

de Waal Malefyt R, Haanen JS, Spits H, Roncarolo M-G, te Velde A, Figdor C, Johnson K, Kastelein R, Ysel H, de Vries JE (1991b) Interleukin 10 (IL-10) and viral IL-10 strongly reduce antigen-specific human $\mathrm{T}$ cell proliferation by diminishing the antigen presenting capacity of monocytes via downregulation of class II major histocompatibility complex expression. J Exp Med 174:915-924.

Ding L, Shevach EM (1992) IL-10 inhibits mitogen induced T cell proliferation by selectively inhibiting macrophage costimulatory function. J Immunol 148:3133-3139.

Ding L, Linsey PS, Huang L-Y, Gsermain RN, Shevach EM (1993) Il-10 inhibits macrophage costimulatory activity by selectively inhibiting the up-regulation of B7 expression. J Immunol 151:1224-1234.

Eng LF, Ghirnikar RS (1994) GFAP and astrogliosis. Brain Pathol 4:229-237.

Fiorentino DF, Zlotnik A, Mosmann TR, Howard M, O'Garra AO (1991a) IL-10 inhibits cytokine production by activated macrophages. J Immunol 147:3815-3822.

Fiorentino DF, Zlotnik A, Viera P, Mosmann TR, Howard M, Moore KW, O'Garra (1991b) IL-10 acts on the antigen-presenting cell to inhibit cytokine production by Th1 cells. J Immunol 146:3444-3451.

Frei K, Lins H, Schwerdel C, Fontana A (1994) Antigen presentation in the central nervous system: the inhibitory effect of IL-10 on MHC class II expression and production of cytokines depends on the inducing signals and the type of cell analyzed. J Immumul 152:2720-2728.

Giulian D (1987) Ameboid microglia as effectors of inflammation in the central nervous system. J Neurosci Res 18:155-171.

Giulian D, Lachman LB (1985) Interleukin-1 stimulation of astroglial proliferation after brain injury. Science 228:497-498.

Giulian D, Robertson C. (1990) Inhibition of mononuclear phagocytes reduces ischemic injury in the spinal cord. Ann Neurol 27:33-42.

Giulian D, Woodward J, Yong DG, Krebs JF, Lachman LB (1988) Interleukin-1 injected into mammalian brain stimulates astrogliosis and neovascularization. J Neurosci 8:2485-2490.

Giulian D, Chen J, Ingeman JE, George J, Noponen M (1989) The role of mononuclear phagocytes in wound healing after traumatic injury to adult mammalian brain. J Neurosci 9:4416-4429.

Ip NY, Wiegand SJ, Morse J, Rudge JS (1993) Injury-induced regulation of ciliary neurotrophic factor $\mathrm{mRNA}$ in the adult rat brain. Eur $\mathbf{J}$ Neurosci 5:25-33.

Kitamura T, Hattori H, Fujita S (1972) Autoradiographic studies of histogenesis of brain macrophages in the mouse. J Neuropathol Exp Neurol 31:502-518.

Kobayashi M, Fitz L, Ryan M, Hewick RM, Clark SC, Chan S, Loudon R, Sherman F, Perussia B, Trinchieri G (1989) Identification and purification of natural killer cell stimulatory factor (NKSF), a cytokine with multiple biologic effects on human lymphocytes. J Exp Med 170:827-845. 
Larsen CA, Anderson AO, Appella E, Oppenheim JJ, Matsushima KK (1989) The neutrophil-activating protein (NAP-1) is also chemotactic for T lymphocytes. Science 243:1464-1466.

Leong SK, Ling E-A (1992) Amoeboid and ramified microglia and their interrelationship and response to brain injury. Glia 6:39-47.

Liuzzi FJ, Lasek RJ (1987) Astrocytes block axonal regeneration in mammals by activating the physiological stop pathway. Science 237:642-645

Maxwell WL, Follows R, Ashhurst DE, Berry M (1990) The response of the cerebral hemisphere of the rat to injury. II. The neonatal rat. Philos Trans R Soc Lond Biol 328:501-513.

Mizuno T, Sawada N, Marunouchi T, Suzumura $\Lambda$ (1994) Production of interleukin- 10 by mouse glial cells in culture. Biochem Biophys Res Commun 205:1907-1915.

Moore KW, Viera P, Fiorentino DF, Trounstine ML, Khan TA, Mosmann TR (1990) Homology of cytokine synthesis inhibitory factor (IL-10) to the Epstein-Barr virus gene BCRF1. Science 248:1230-1234.

Moorshead CM, van der Kooy D (1990) Separate blood and brain origins of proliferating cells during gliosis in adult brains. Brain Res 535:237-244.

Mori S, Leblond CP (1969) Electron microscopic features and proliferation of astrocytes in the corpus callosum of the rat. J Comp Neurol 137:197-225.

Mosmann TR (1994) Properties and functions of interleukin-10. Adv Immunol 56:1-26.

Mosmann TR, Schumacher JH, Fiorentino DF, Leverah J, Moore KW, Bond MW (1990) Isolation of mAbs specific for IL-4, IL-5, and IL-6, and a new TH2-specific cytokine, cytokine synthesis inhibitory factor (CSIF, IL-10) using a solid phase radioimmunoadsorbent assay. J Immunol 145:2938-2945.

Nathaniel EJ, Nathaniel DR (1981) The reactive astrocyte. Adv Cell Neurobiol 2:249-301.

Needels DL, Nieto-Sampedro M, Cotman CW (1986) Induction of a neurite-promoting factor in rat brain following injury or deafferentation. Neuroscience 18:517.

Nieto-Sampedro M, Lewis ER, Cotman EW, Manthrope M, Skaper SD, Barbin G, Longo FM, Varon S (1982) Brain-injury causes a timeindependant increase in neurotrophic activity at the lesion site. Science $217: 860-861$

Nieto-Sampedro M, Manthrope M, Barbin G, Varon S, Cotman CW (1983) Injury-induced neuronotrophic activity in adult rat brain: correlation with survival of delayed implants in the wound cavity. J Neurosci 3:2219-2229.

Norenberg MD (1994) Astrocyte response to CNS injury. J Neuropathol Exp Neurol 53:213-220.

Norton WT, Aquino DA, Hozuni I, Chiu F-C, Brosnan CF (1992) Quantitative aspects of reactive gliosis: a review. Neurochem Res 17:877-885.

O'Garra A, Stapleton G, Dhar V, Pearce M, Schumacher J, Rugo H, Barbis D, Stall A, Cupp J, Moore K, Vieira P, Mosmann TR, Whitmore $\Lambda, \Lambda$ rnold L, Haughton G, Howard M (1990) Production of cytokines by mouse B cells: $B$ lymphomas and normal B cells produce interleukin10. Int Immunol 2:821-832.

Oh YJ, Markelonis GJ, Oh TH (1993) Effects of interleukin-1 $\beta$ and tumor necrosis factor- $\alpha$ on the expression of glial fibrillary acidic protein and transferrin in cultured astrocytes. Glia 8:77-86.

Pollen DA, Trachtenberg MC (1970) Neuroglia: gliosis and focal epilepsy. Science 167:1252-1253.

Quan N, Sundar SK, Weiss JM (1994) Induction of interleukin-1 in various brain regions after peripheral and central injections of lipopolysaccharide. J Neuroimmunol 49:125-134.

Raine CS, Bornstein MB (1970) EAE: a light and electron microscope study of remyelination and "sclerosis" in vitro. J Neuropathol Exp Neurol 29:552-574.

Reier PJ, Stensaas LJ, Guth L (1983) The astrocytic scar as an impediment to regeneration in the central nervous system. In: Fundamentals of spinal cord reconstruction (Kao CC, Bunge RP, Reier PJ, eds), p 163. New York: Raven.

Renno T, Krakowski M, Piccirillo C, Lin JY, Owens T (1995) TNF- $\alpha$ expression by resident microglia and infiltrating leukocytes in the cen tral nervous system of mice with experimental allergic encephalomyelitis-regulation by Th1 cytokines. J Immunol 154:944-953.

Rott O, Fleisher B, Cash E (1994) Interleukin-10 prevents experimental allergic encephalomyelitis in rats. Eur J Immunol 24:1434-1440.
Rubio N, de Felipe C (1991) Demonstration of the presence of a specific interferon-receptor on murine astrocyte cell surface. J Neuroimmunol 35:111-117.

Sawada M, Itoh Y, Suzumura A, Marunouchi T (1993) Expression of cytokine receptors in cultured neuronal and glia cells. Neurosci Lett 160:131-134

Selmaj KW, Farooq M, Norton WT, Raine CS, Brosnan CF (1990) Proliferation of astrocytes in vitro in response to cytokines: a primary role for tumor necrosis factor. J Immunol 144:129-135.

Singer-Sam J, Robinson MO, Bellve AR, Simon MI, Riggs AD (1990) Measurement by quantitative PCR of changes in HPRT, PGK-1, PGK-2, APRT, MTase and Zfy gene transcripts during mouse spermatogenesis. Nucleic Acids Res 18:1255-1259.

Springer TA, Galfre G, Secher DS, Milstein C (1979) Mac-1: a macrophage differentiation antigen identified by monoclonal antibody. Eur J Immunol 9:301-306.

Sumi SM, Hager H (1968) Electron microscopic study of the reaction of the newborn rat brain to injury. Acta Neuropathol (Berl) 10:324-335.

Sylvester I, Rankin JA, Yoshimura T, Tanaka S, Leonard S (1990) Secretion of neutrophil attractant/activation protein by lipopolysaccharide-stimulated lung macrophages determined by both enzyme-linked immunosorbent assay and N-terminal sequence analysis. Am Rev Respir Dis 141:683-688.

Tada M, Diserens AC, Desbaillets I, de Tribolet N (1994) Analysis of cytokine receptor messenger RNA expression in human glioblastoma cells and normal astrocytes by reverse-transcription polymerase chain reaction. J Neurosurg 80:1063-1073.

Taupin V, Toulmond S, Serrano A, Benavides J, Zavala F (1993) Increase in IL-6, IL-1, and TNF- $\alpha$ levels in rat brain following traumatic esion. Infuence of pre- and post-traumatic treatments with Ro5 4864: a peripheral-type ( $\mathrm{p}$-site) benzodiazepine ligand. J Neuroimmunol 42:177-186.

Tchelingerian JL, Qunonero J, Booss J, Jacque C (1993) Localization of TNF $\alpha$ and IL- $1 \alpha$ immunoreactivities in striatal neurons after surgical injury of the hippocampus. Neuron 10:213-224.

Thanos S, Mey J, Wild M (1993) Treatment of the adult retina with microglia-suppressing factors retards axotomy-induced neuronal degradation and enhances axonal regeneration in vivo and in vitro. J Neurosci 13:455-456

Tripp CS, Wolf SF, Unanue ER (1993) Interleukin 12 and tumor necrosis factor alpha are costimulators of interferon gamma production by natural killer cells in severe combined immunodeficiency mice with listeriosis, and interleukin 10 is a physiologic antagonist. Proc Natl Acad Sci USA 90:3725-3729.

Tsuchihushi Y, Kitamura T, Fujita S (1981) Immunofluorescence studies of the monocytes in the injured rat brain. Acta Neuropathol (Berl) 53:213-219.

Vaughn JE, Pease DC (1967) Electron microscopy of classically stained astrocytes. J Comp Neurol 131:143-154.

Watts RG, Wright JL, Atkinson LL, Merchant RE (1989) Histopathological and blood-brain barrier changes in rats induced by an intracerebral injection of human recombinant interleukin-2. Neurosurgery 25:202-208.

Woodroofe MN, Sarna GS, Wadha M, Hayes GM, Loughlin AJ, Tinker A, Cuzner ML (1991) Detection of interleukin-1 and interleukin-6 in adult rat brain, following mechanical injury, by in vivo microdialysis: evidence of a role for microglia in cytokine production. $\mathbf{J}$ Neuroimmunol 33:227-236.

Yan HQ, Banos MA, Herregodts P, Hooghe R, Hooghe-Peters EL (1992) Expression of interleukin (IL)- $1 \beta$, IL- 6 and their respective receptors in the normal rat brain and after injury. Eur J Immunol 22:2963-2971.

Yong VW, Balasingam V (1995) Cytokines as mediators of reactive astrogliosis. Methods Neurosci 24:220-235.

Yong VW, Moumdjian R, Yong FP, Ruijs TCG, Freedman MS, Cashman N, Antel JP (1991) Gamma-interferon promotes proliferation of adult human astrocytes in vitro and reactive gliosis in the adult mouse brain in vitro. Proc Natl Acad Sci USA 88:7016-7020.

Yong VW, Tejada-Berges T, Goodyer CG, Antel JP, Yong FP (1992) Differential proliferative response of human and mouse astrocytes to gamma-interferon. Glia 6:269-280.

Yong VW (1996) Cytokines, astrogliosis, and neurotrophism following CNS trauma. In: Cytokines and the CNS: development, defense and disease (Ransohoff R, Bcnvenistc E, cds), pp 309-327. Boca Raton, FL: CRC.

Yoshimura T, Matsushima K, Tanaka S, Robinson EA, Apella E, Oppenheim JJ, Leonard EJ (1987) Purification of a human monocyte derived neutrophil chemotactic factor that has peptide sequence similarity to other host defense cytokines. Proc Natl Acad Sci USA 84:9233-9237. 